\title{
H-type tracheoesophageal fistula in the neonatal period: Difficulties in diagnosis and different treatment approaches. A case series
}

\author{
Giselle Cuestas, M.D. ${ }^{a}$, Verónica Rodríguez, M.D. ${ }^{a}$, Carolina Millán, M.D. ${ }^{b}$, Patricio Bellia Munzón, \\ M.D. ${ }^{a}$ and Gastón Bellia Munzón, M.D. ${ }^{b, c}$
}

\begin{abstract}
Congenital tracheoesophageal fistula not associated with esophageal atresia, known as H-type fistula, is an uncommon anomaly. It presents with cough, choking, and cyanosis during feeding and/or recurrent pneumonia.

Although symptoms are usually present from birth, diagnosis is difficult. The rarity of this disease, non-specific symptoms, and the limitations of radiological and endoscopic confirmation of the fistula often result in a delay between presentation and diagnosis confirmation. Here we describe the clinical manifestations, assessment methods, and management of 3 newborn infants with $\mathrm{H}$-type tracheoesophageal fistula, together with diagnosis recommendations to prevent unnecessary delays in the management of this condition.

Key words: H-type tracheoesophageal fistula, newborn infant, bronchoscopy, thoracoscopy.
\end{abstract}

http: / / dx.doi.org/ 10.5546/ aap.2020.eng.56

To cite: Cuestas G, Rodríguez V, Millán C, Bellia Munzón P, Bellia Munzón G. H-type tracheoesophageal fistula in the neonatal period: Difficulties in diagnosis and different treatment approaches. A case series. Arch Argent Pediatr 2020;118(1):56-60.

a. Unit of Respiratory Endoscopy, Ear, Nose and Throat Department, Hospital General de Niños "Dr. Pedro de Elizalde," Autonomous City of Buenos Aires, Argentina.

b. Department of Pediatric Surgery, Fundación Hospitalaria, Autonomous City of Buenos Aires, Argentina.

c. Department of Surgery, Hospital General de Niños "Dr. Pedro de Elizalde," Autonomous City of Buenos Aires, Argentina.

E-mail address: Giselle Cuestas: giselle_cuestas@yahoo.com.ar

Funding: None.

Conflict of interest: None.

Received: 5-9-2019

Accepted: 8-16-2019

\section{INTRODUCTION}

Tracheoesophageal fistula (TEF) is associated with esophageal atresia (EA) in $95 \%$ of cases. Its incidence is approximately 1 in 3500 live births, and it is slightly more frequent among males. ${ }^{1}$

H-type TEF not associated with EA-type V according to Ladd and Gross' classificationis a rare airway anomaly that accounts for $4 \%$ of all tracheoesophageal malformations. ${ }^{2,3}$ It is an abnormal communication in an oblique course that looks like an $\mathrm{N}$, located between the posterior wall of the trachea (cranial orifice) and the anterior wall of the esophagus (caudal orifice). ${ }^{4}$ In general, it is located in the cervical region or in the thoracic inlet; the incidence of associated congenital malformations is lower and it has a better prognosis among the different types of TEF. 5,6

Although some articles have mentioned cases in the neonatal period, several authors have described a late diagnosis, even in adult age. ${ }^{3,7,8}$ An early diagnosis is still a challenge for pediatricians because of the rarity of the condition and the non-specificity of symptoms. These may be subtle and intermittent due to the anatomical characteristics of the fistula (oblique course, small orifice, and the redundant nature of esophageal mucosa, which may transiently obstruct it) and are frequently attributed to more common etiologies, like gastroesophageal reflux (GER) and swallowing disorders or a poor feeding technique. ${ }^{9,10}$

The classical clinical triad of H-type TEF includes cough fits, cyanosis, and choking during feeding, abdominal distension, and recurrent respiratory tract infections..$^{4-6}$ Diagnosis requires a high rate of clinical suspicion, and confirmation is made through imaging tests, such as an upper gastrointestinal tract study with contrast and a videofluoroscopy, or a tracheobronchoscopy, which provides a direct view of the fistula. ${ }^{4}$

None of these imaging tests has a sensitivity of $100 \%$. Special positioning and contrast administration techniques have been described to aid in diagnosis. ${ }^{3,9}$ Several studies have proposed 
that an endoscopy is the fundamental diagnostic technique to confirm the presence of a fistula and locate its level accurately. ${ }^{11}$ Surgery is the main treatment modality, and cervical or thoracic approach depends on the level of the fistula. ${ }^{5}$

\section{CASE REPORTS}

Here we report the cases of 3 male patients with H-type TEF seen between February 2016 and February 2019. The characteristics of patients are summarized in Table 1. All patients had symptoms present at birth and had been diagnosed between 9 and 30 days of life.

A videofluoroscopic swallowing study (VFSS) showed the passage of contrast into the trachea in 2 patients, but the level of the fistula was accurately determined only in 1 of them (Figure 1.A). A rigid tracheobronchoscopy under general anesthesia using a 0 -degree and 5-mm optical scope confirmed the diagnosis of H-type fistula in all patients (Figures 1.B and 1.C). For diagnostic purposes, 2 patients had an endotracheal tube with balloon placed in the esophagus, then the balloon was inflated, thus obstructing the esophageal lumen. A bronchoscope tube was placed to ventilate the patient; the optical scope was introduced through the tube to check that the convexity of the posterior wall of the trachea (due to the inflated balloon in the esophagus) was distal to the potential fistula area. After injecting air, saline solution was instilled using a catheter placed in the esophagus above the balloon. The presence of a fistula was confirmed if air and saline solution bubbles were observed in the trachea (Figure 2).

Two patients were fed with a nasogastric tube (NGT) until the moment of the surgical repair. The remaining patient had a Nissen fundoplication and gastrostomy due to severe GER; an endoscopic closure of the fistula with

TABLE 1. Characteristics of patients with H-type fistula

\begin{tabular}{|c|c|c|c|c|c|c|c|c|c|c|}
\hline \multirow[t]{2}{*}{$\bar{P}$} & \multirow{2}{*}{$\begin{array}{l}\text { Clinical } \\
\text { manifestations }\end{array}$} & \multirow[t]{2}{*}{ Associated anomaly } & \multirow{2}{*}{$\begin{array}{l}\text { Age at the } \\
\text { time of } \\
\text { diagnosis }\end{array}$} & \multirow[t]{2}{*}{ Imaging tests } & \multirow[t]{2}{*}{ Bronchoscopy } & \multirow{2}{*}{$\begin{array}{l}\text { Prior } \\
\text { treatment }\end{array}$} & \multirow{2}{*}{$\begin{array}{l}\text { Age at the } \\
\text { time of } \\
\text { surgery }\end{array}$} & \multicolumn{2}{|c|}{ Surgical treatment } & \multirow[t]{2}{*}{ Complications } \\
\hline & & & & & & & & Approach & Technique & \\
\hline 1 & $\begin{array}{l}\text { Choking with } \\
\text { feeding } \\
\text { Pneumonia }\end{array}$ & $\begin{array}{l}\text { Iris discoloration } \\
\text { Polydactyly } \\
\text { Tracheomalacia }\end{array}$ & 30 days old & VFSS: normal & Cervical fistula & $\begin{array}{l}\text { Endoscopic } \\
\text { closure of } \\
\text { the fistula } \\
X 3\end{array}$ & 2 years old & Cervical & $\begin{array}{l}\text { Ligation and } \\
\text { sectioning of } \\
\text { the fistula }\end{array}$ & No \\
\hline 2 & $\begin{array}{l}\text { Choking with } \\
\text { feeding }\end{array}$ & Tracheomalacia & 20 days old & $\begin{array}{l}\text { VFSS: passage } \\
\text { of contrast } \\
\text { into the } \\
\text { trachea }\end{array}$ & $\begin{array}{l}\text { Intrathoracic } \\
\text { fistula }\end{array}$ & No & 27 days old & Thoracoscopy & $\begin{array}{l}\text { Ligation and } \\
\text { clipping of the } \\
\text { fistula without } \\
\text { sectioning }\end{array}$ & No \\
\hline 3 & $\begin{array}{l}\text { Choking with } \\
\text { feeding }\end{array}$ & Tracheomalacia & 9 days old & \begin{tabular}{|l|} 
VFSS: \\
aspiration and \\
fistula \\
identification
\end{tabular} & $\begin{array}{l}\text { Intrathoracic } \\
\text { fistula }\end{array}$ & No & 17 days old & Thoracoscopy & $\begin{array}{l}\text { Ligation and } \\
\text { sectioning of } \\
\text { the fistula }\end{array}$ & $\begin{array}{l}\text { Pneumothorax } \\
\text { Partial dehiscence } \\
\text { of the suture } \\
\text { Diaphragmatic } \\
\text { paralysis } \\
\text { Cord paralysis }\end{array}$ \\
\hline
\end{tabular}

Figure 1. A. Videofluoroscopic swallowing study. Passage of contrast into the trachea (arrow) and fistula identification (circle). B and C. Endoscopic images of the tracheal orifices of an H-type tracheoesophageal fistula (B) and a fistula associated with esophageal atresia $(C)$ (arrows). B. Small round orifice in the posterior wall of the cervical trachea. C. Larger orifice in the distal (supracarinal) trachea

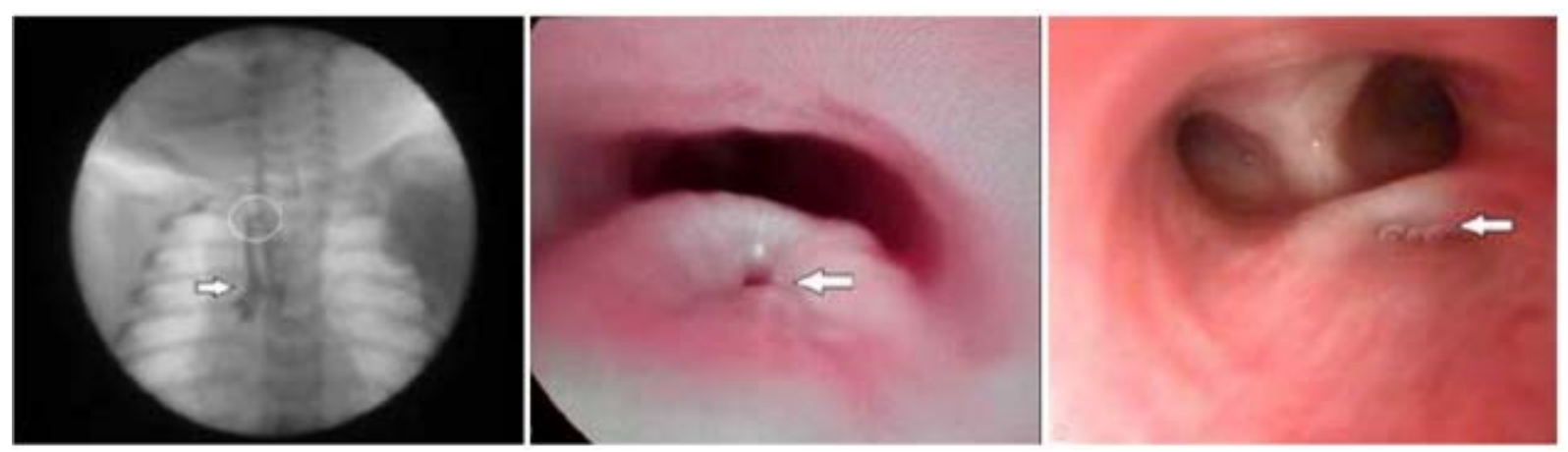


silver nitrate was attempted 3 times due to the low morbidity of this procedure. Given the recurrent fistula, it was decided to perform a surgery. Channeling of the fistula with guidewire to facilitate intraoperative identification was performed in the 3 patients (Figure 3).

In the post-operative period, the patients were hospitalized in the intensive care unit for 7 days and extubated on day 3. Two patients showed a favorable course. The remaining patient developed pneumothorax due to partial dehiscence of the suture. Six tracheal rings were resected with endto-end anastomosis, closure of the esophageal wall, and interposition of the thymus via cervicotomy 9 days later. The patient evolved with left diaphragmatic and cord paralysis, which were managed through diaphragmatic plication and liquid thickening, respectively.

The follow-up period ranged from 3 months to 2 years. No patient had symptoms recurrence during follow-up. They are fed per os and have a normal height and weight growth for their age.

\section{DISCUSSION}

Congenital TEF is the result of a defective separation of the respiratory and digestive tracts during embryogenesis. ${ }^{7}$ The etiology of this entity is multifactorial. ${ }^{11}$ There are 5 anatomical types, with proximal EA with distal TEF being the most common one $(90 \%) .{ }^{1}$ Isolated or H-type forms are rare.

The clinical presentation of $\mathrm{H}$-type fistulas is related to their caliber. ${ }^{12,13}$ Large fistulas present with respiratory distress due to gastric distension and persistent airway secretions, whereas small ones are accompanied with recurrent cyanosis episodes due to saliva and milk aspiration. Symptoms improve when using a NGT for feeding. A fistula presents in a delayed manner as recurrent or persistent respiratory tract infections,

FIGURE 2. A and B. Tracheal orifice of the H-type tracheoesophageal fistula before $(A)$ and after (B) injecting air (arrow) through a catheter above the inflated balloon of an endotracheal tube placed in the esophagus. Mucosal congestion (tracheitis) secondary to secretion aspiration is also seen. $C$ and D. Tracheal orifice of the H-type tracheoesophageal fistula before (C) and after (D) instilling saline solution (arrow) through a catheter above the inflated balloon of an endotracheal tube placed in the esophagus.

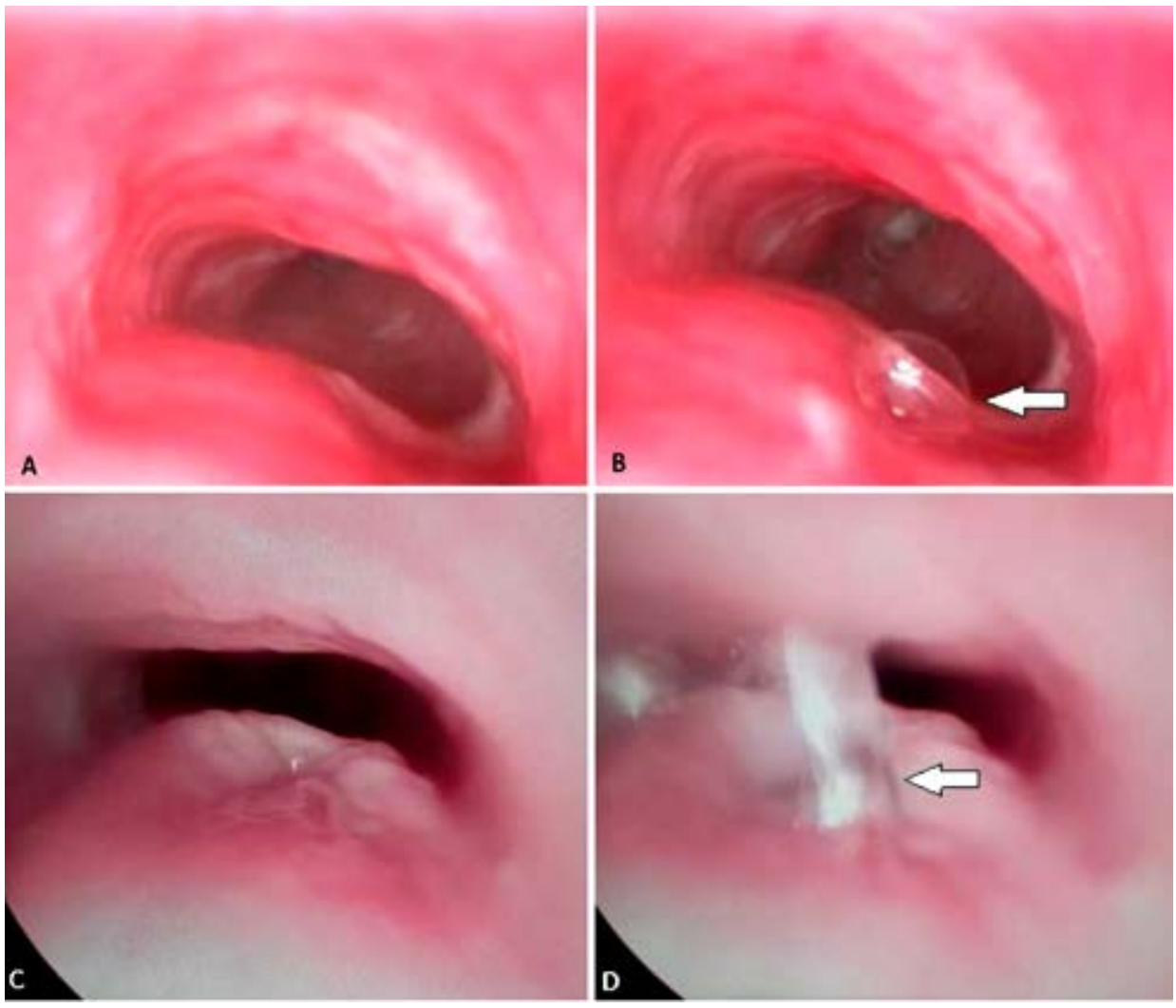


chronic obstructive pulmonary disease, and bronchiectasis secondary to aspiration. ${ }^{6}$

A chest X-ray may be useful to look for signs of aspiration and air in the lower esophagus. ${ }^{6,7} \mathrm{~A}$ computed tomography is recommended to assess the lung parenchyma and sometimes helps to evidence the fistula. ${ }^{14}$

Contrast tests of the upper gastrointestinal tract (upper gastrointestinal series or VFSS) are part of routine care when an H-type fistula is suspected. ${ }^{4,9}$ Their sensitivity ranges from $50 \%$ to $73 \% .^{12}$ For a greater sensitivity, it is recommended to perform the test with the patient in the prone position and to insert a NGT and withdraw it while injecting a contrast agent at different levels of the esophagus. This technique requires video or rapid sequence films. ${ }^{4,510,12}$ Due to the risk for aspiration, it is recommended to use a watersoluble contrast and have adequate resuscitation equipment readily available. ${ }^{4,12}$

In case of high clinical suspicion, a tracheobronchoscopy is the definite diagnostic test. ${ }^{5,9}$ It allows to identify and locate the fistula and to assess the presence of associated airway anomalies (e.g., tracheomalacia, laryngeal cleft, stenosis, cord paralysis or a second fistula). ${ }^{4,5,7}$

The fistula is viewed as a small round opening in the midline of the posterior membranous wall of the trachea, generally at the cervical level or in the thoracic inlet. ${ }^{4}$ Secretions are commonly present in the airway.

To improve the test's performance, it is recommended to insert an endotracheal tube with balloon in the esophagus and inject air and / or instill saline solution using a catheter placed in the esophagus above the inflated balloon. The presence of a fistula is confirmed if air and/or saline solution bubbles are observed in the trachea. Other authors had opted to instill methylene blue to see the fluid passage. ${ }^{12}$

An endoscopy allows to channel the fistula (with a ureteral or Fogarty catheter or guidewire), thus facilitating its identification during surgical repair. An esophagoscopy is not recommended to diagnose a TEF because the esophageal orifice is too small and the esophageal mucosal folds hinder visualization. ${ }^{5}$

Diagnosis improves significantly with tracheobronchoscopy. However, radiological and endoscopic techniques complement each other, and using both warrants the identification of an H-type fistula. ${ }^{5}$ The differential diagnosis should include GER, swallowing disorders, laryngeal cleft, esophageal stenosis, and extrinsic esophageal compression. ${ }^{12}$

The treatment of choice is surgical repair. The cervical approach is indicated for fistulas above the second thoracic vertebra, whereas the thoracic approach, for those at a more caudal level., ${ }^{5,12,14}$

The thoracoscopic approach has certain advantages over the conventional thoracotomy: a greater visibility of the field thanks to magnification, lower post-operative pain levels, and improved aesthetic outcomes. ${ }^{3}$ It is a minimally invasive technique, but it is complex and requires experienced providers.

The most common post-operative complications include suture dehiscence, recurrent nerve damage, and lung complications secondary to GER, tracheomalacia, esophageal
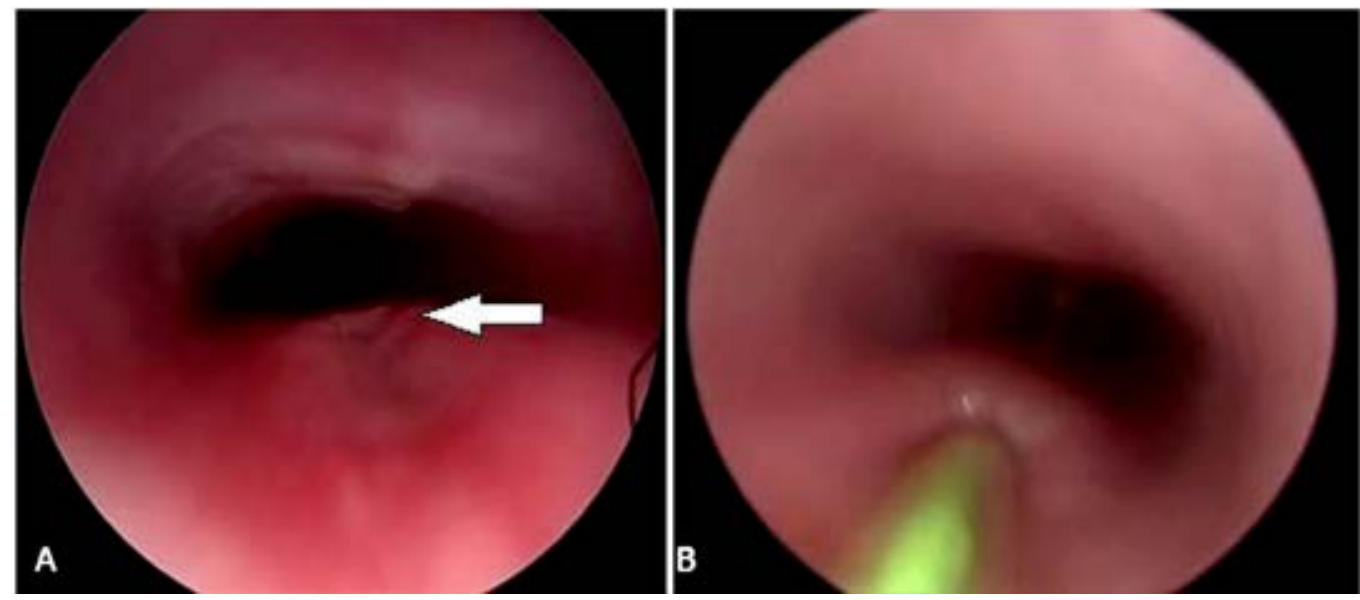
stenosis or TEF recurrence. ${ }^{6,12}$

In addition, $30 \%$ of TEF are associated with other anomalies of the digestive, urogenital and / or cardiovascular system, including vertebral defects, anal atresia, cardiac defects, tracheoesophageal fistula, renal anomalies, and limb abnormalities (VACTERL/VATER association) and coloboma, heart defects, choanal atresia, retardation of growth, genital abnormalities, and ear abnormalities (CHARGE). ${ }^{2,5}$ Comorbidities determine prognosis, which is otherwise very good. ${ }^{12}$

The diagnosis of H-type fistulas implies a high rate of clinical suspicion in newborn infants with cough and cyanosis during feeding and recurrent respiratory symptoms. A rigid tracheobronchoscopy may be considered the method of choice for diagnostic confirmation. A multidisciplinary approach is critical for an early diagnosis and a timely management of H-type fistulas.

\section{REFERENCES}

1. Palacios Sánchez M, Alegría Echauri I, Alegría Echauri E, Pérez Belmonte E, et al. Fístula en H: a propósito de un caso. Bol Pediatr. 2013; 53(223):41-4.

2. Riazulhaq M, Elhassan E. Early recognition of h-type tracheoesophageal fistula. APSP J Case Rep. 2012; 3(1):4.

3. González TempranoN, Viguria Sánchez N, Ayuso González L, Pérez Martínez A. Fístula traqueoesofágica en $\mathrm{H}$ en periodo neonatal: diferentes abordajes terapéuticos. $A n$ Pediatr (Barc). 2014; 81(6):e50-1.
4. Ng J, Antao B, Bartram J, Raghavan A, et al. Diagnostic difficulties in the management of H-type tracheoesophageal fistula. Acta Radiol. 2006; 47(8):801-5.

5. Jaiswal AA, Garg AK, Mohanty MK. 'H' type tracheo-oesophageal fistula. Case reports with review of the literature. EJENTAS. 2014; 15(2):143-8.

6. Parakh H, Kapoor MS, Sharma D, Pandita A, et al. H-type tracheo-esophageal fistula in a very low birth weight infant: An unexpected and diagnostic challenge for neonatologist. Med J DY Patil Univ. 2015; 8(3):354-7.

7. Aygun D, Emre S, Nepesov S, Tekant G, et al. Presentation of H-type tracheoesophageal fistula in two adolescents: Delayed diagnosis. Pediatr Neonatol. 2017; 58(2):187-8.

8. Antabak A, Luetic T, Caleta D, Romic I. H-type tracheoesophageal fistula in a newborn: Determining. the exact position of fistula by intra-operative guidewire placement. J Neonatal Surg. 2014; 3(3):36.

9. LeeSYS, Hamouda ESM. H-type tracheoesophageal fistula diagnosed on video fluoroscopy swallowing study. BMJ Case Rep. 2018; 11(1):bcr 2018227794.

10. Perry M, Eick J, Jakob K, Adolph V, et al. Clinical images - a quarterly column: early presentation of h-type tracheoesophageal fistula. Ochsner J. 2013; 13(4):483-5.

11. Donnelly P, McVea S, Flannigan C, Bali S. Incidental diagnosis of an H-type tracheo-oesophageal fistula. BMJ Case Rep. 2016;2016:bcr2016215419.

12. Morales Múnera OL, Valencia Chaves ML, Roya Pabón CL, Niño Serna LF. Fístula traqueoesofágica en niños: un diagnóstico para tener en cuenta. Reporte de dos casos y revisión de la literatura. IATREIA. 2013; 26(3):346-55.

13. Harjai MM, Holla RG, Kale R, Sharma YK. H-type tracheooesophageal fistula. Arch Dis Child Fetal Neonatal Ed. 2007; 92(1):F40.

14. Stavroulias D, Ampollini L, Carbognani P, Rusca M. Late presentation of congenital $\mathrm{H}$-type tracheoesophageal fistula in an immunocompromised patient. Eur J Cardiothorac Surg. 2011; 40(2):e98-100 